\title{
The New Australian Concrete Structures Standard AS 3600:2018 - Aspects of its Complexity and Effectiveness
}

\author{
By Sanaul Chowdhury ${ }^{*} \&$ Yew-Chaye Loo ${ }^{\dagger}$
}

Providing design guides, the first of the AS 3600 standard series, Australian Standard for Concrete Structures AS 3600-1988 was published in March 1988. Since then, AS 3600 has been revised four times and published consecutively at between six to nineyear intervals as AS 3600-1994, AS 3600-2001, AS 3600-2009 and the latest, AS 36002018. The changes and/or updates made in AS 3600-2018 are mainly in the following requirements:

- Stress-block configuration for bending analysis and design of reinforced and prestressed members

- Shear and torsional strengths of members

- Values of capacity reduction factor, $\phi$, for different member strengths

- Effective moment of inertia for deflection calculations

Most of the abovementioned modifications have resulted in more complicated procedures and additional computational efforts. Academically, such added complexity might be considered as a disciplinary upgrade. On the other hand, the practitioners deserve to be advised of the effectiveness, or worthiness, of such an advance. In each of the concerned topics, analysis and design calculations have been carried out using the updated specifications given in AS 3600-2018, as well as those available in the superseded AS 3600-2009. Based on the numerical data and design outcomes, observations are made in this paper regarding the complexity and effectiveness of this the latest version of Australia's premier concrete structures code.

Keywords: AS 3600-2018, Australian Standards, Complexities, Concrete Structures, Design Effectiveness.

\section{Introduction}

The ultimate strength theory underpins the analysis and design of reinforced and prestressed concrete structures and has been since the promulgation of Australia's Concrete Structures Standard, Australian Standard (AS) 3600-1988 Concrete Structures. The first of this AS 3600 series, was published in March 1988. In line with European practices, it was a unified code covering reinforced and prestressed concrete structures. In effect, AS 3600-1988 Concrete Structures was the revised and amalgamated version of AS 1480-1982 SAA Concrete Structures Code and AS 1481-1978 SAA Prestressed Concrete Code, which it then superseded. Limit state design philosophy was adopted in AS 3600-1988. In practice, especially in strength design, engineers familiar with AS 1480-1982 could make the changeover without too much difficulty. Many of the design equations for shear, torsion,

\footnotetext{
*Senior Lecturer, School of Engineering \& Built Environment, Griffith University, Australia. †Professor Emeritus, School of Engineering \& Built Environment, Griffith University, Australia.
} 
slabs and columns were changed, but the strength design procedure was basically the same, that is, to ensure

$$
\phi R_{\mathrm{u}} \geq S^{*}
$$

where for a given section of any structural member to be designed, $S^{*}$ was the 'action effect' or axial force, moment, shear or torsion due to the most critical combination of the external service loads, each multiplied by a corresponding load factor; $R_{\mathrm{u}}$ was the computed ultimate resistance (or strength) of the member at that section against the said type of action effect; and $\phi$ was the capacity reduction factor specified for the type of ultimate strength in question.

Since 1988, AS 3600 has been revised and updated four times and published consecutively at approximately six to nine-year intervals as AS 3600-1994, AS 3600-2001, AS 3600-2009, and the latest AS 36002018. However, the limit state design philosophy remains unchanged in the latest version of the Standard in which Clause 2.2.2 states that

$$
R_{\mathrm{d}} \geq E_{\mathrm{d}}
$$

where $R_{\mathrm{d}}=\phi R_{\mathrm{u}}$ is the 'design capacity', and $E_{\mathrm{d}}=S^{*}$, the design action effect.

In AS 3600-2001, which appeared in 2002, N-grade or $500 \mathrm{MPa}$ steel was specified, leading to modifications in serviceability specifications and other consequential changes. In AS 3600-2001, an additional strength grade for concrete was introduced with the characteristic compressive strength $f_{c}^{\prime}=65 \mathrm{MPa}$. Two more grades were provided in AS 3600-2009, i.e. $f_{\mathrm{c}}^{\prime}=80$ $\mathrm{MPa}$ and $100 \mathrm{MPa}$. This has resulted in modification to many of the design equations. However, these design equations are further modified and/or made more complex in some cases in AS 3600-2018.

The changes and/or updates made in AS 3600-2018 are mainly in the following requirements:

- Stress-block configuration for the analysis and design of reinforced and prestressed members in bending.

- Values of capacity reduction factor, $\phi$, for different member strengths.

- Shear and torsional strengths of members.

- Effective moment of inertia for deflection calculations.

Being a rather mature discipline, research worldwide on the mechanics and strength of concrete structures is sustaining a state of diminishing return. Australia is no exception. The abovementioned modifications have resulted in more complicated procedures and added computational efforts. Academically, such increased complexity might be considered as a disciplinary upgrade. On the other hand, the practitioners deserve to be advised of the effectiveness, or worthiness, of such an advance.

In view of the above, for each of the concerned topics, analysis and design calculations have been carried out using the updated specifications given in AS 3600-2018, as well as those available in the superseded AS 3600-2009. Based on the numerical data and design outcomes, observations 
are made in this paper regarding the complexity and effectiveness of this the latest version of Australia's premier concrete structures code.

\section{Concrete Stress Block and Capacity Reduction Factor - A Review}

Design of reinforced concrete for flexure is traditionally performed using a rectangular stress block that simulates compressive stresses in concrete. Because of its simplicity and relative accuracy, the use of the rectangular stress block is recommended in many major national concrete structures codes, including AS 3600 series. It is well established that the stress-strain characteristics of concrete change with strength (Ibrahim and MacGregor 1997, Kaar et al. 1978, Nedderman 1973, Ozbakkaloglu and Saatcioglu 2004, Tan and Nguyen 2004, 2005, Barchi et al. 2010, Yan and $\mathrm{Au}$ 2010, Zhu and Su 2010, Ho 2011). Therefore, the rectangular stress block adopted for normal-strength concretes in earlier versions of AS 3600 may not be applicable to high strength concrete. Thus, in AS 3600-2009, with the introduction of higher strength grades of concrete, a new rectangular stress block was incorporated. The stress block parameters have been further modified in AS 3600-2018.

Although the strength design procedure was unchanged from AS 14801982 and AS 1481-1978, the recommended load factors were generally lower in AS 3600 series than previously specified. However, accompanying these lower load factors were the corresponding reduced values of $\phi$. A probabilistic-based analytical model was adopted to re-evaluate the reliability of the then new design procedure. Unfortunately, actual failure statistics were inadequate for the probabilistic analysis to produce a new and more reliable procedure (in terms of load factors and $\phi$ ). Instead, the new procedure was calibrated simply using designs based on the old AS 14801982 code. In simplistic terms, the codes prior to AS 3600 series and after applied in parallel should lead to the same design. However, the values of $\phi$ have been increased in AS 3600-2018 to address this issue.

\section{Complexities}

The widely accepted 'actual' stress block is as shown in Figure 1(a). The factor $\eta<1$ accounts for the difference between the crushing strength of concrete cylinders and the concrete in the beam; $\alpha$ and $\beta$, each being a function of $f_{\mathrm{c}}^{\prime}$, define the geometry of the stress block. Empirical but complicated formulas have been given for $\eta, \alpha$ and $\beta$. Although the concept of the curved stress block was acknowledged as an advance, it was tedious to apply. The equivalent (rectangular) stress block, as shown in Figure 1(b), was so defined that its use would give the same $M_{\mathrm{u}}$ as that computed using the 'actual' stress block. 
Figure 1. (a) Actual Stress Block and (b) Equivalent Stress Block

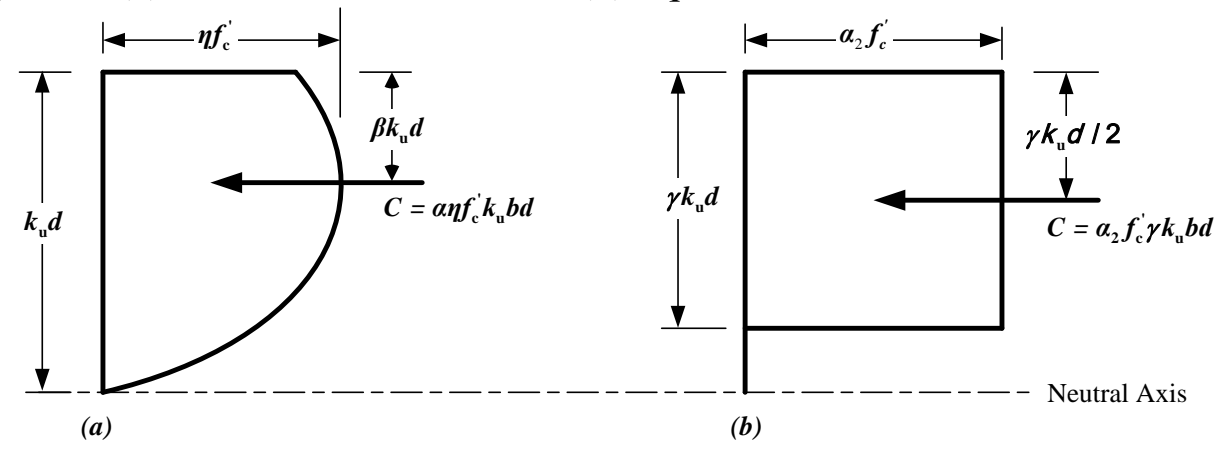

In AS 3600-2009, $\alpha_{2}$ and $\gamma$ for all section types were given as:

$\begin{array}{llr}\alpha_{2}=1.0-0.003 f_{\mathrm{c}}^{\prime} & \text { but } & 0.67 \leq \alpha_{2} \leq 0.85 \\ \gamma=1.05-0.007 f_{\mathrm{c}}^{\prime} & \text { but } & 0.67 \leq \gamma \leq 0.85\end{array}$

In AS 3600-2018, these are changed to:

$\alpha_{2}=0.85-0.0015 f^{\prime} \quad$ but $\quad \alpha_{2} \geq 0.67$

For circular sections, $\alpha_{2}$ is to be reduced by $5 \%$ and for any section for which width reduces from the neutral axis towards the compression face, $\alpha_{2}$ is to be reduced by $10 \%$.

On the other hand, for all section types,

$\gamma=0.97-0.0025 f_{\mathrm{c}}^{\prime} \quad$ but $\quad \gamma \geq 0.67$

In AS 3600-2009, the capacity reduction factor $\phi$ was given as

$$
\phi=1.19-13 k_{\text {чо }} / 12
$$

but for beams with Class $\mathrm{N}$ reinforcement only

$$
0.6 \leq \phi \leq 0.8
$$

and for beams with Class L reinforcement

$$
0.6 \leq \phi \leq 0.64
$$

In Equation (7)a, $k_{\mathrm{uo}}=\frac{k_{\mathrm{u}} d}{d_{\mathrm{o}}}$ in which $d_{\mathrm{o}}$ is the distance between the extreme compression fibre and the centroid of the outermost layer of the tension bars.

In AS 3600-2018, $\phi$ values are changed to: 


$$
\phi=1.24-13 k_{\text {uо }} / 12
$$

but for beams with Class $\mathrm{N}$ reinforcement only

$$
0.65 \leq \phi \leq 0.85
$$

and for beams with Class L reinforcement

$$
\phi=0.65
$$

\section{Effectiveness}

Analysis and design calculations have been carried out using the updated specifications given in AS 3600-2018 and those available in the superseded AS 3600-2009 for several problems. These helps investigate the effectiveness of introducing the complexities as described above in determining $\alpha_{2}, \gamma$ and $\phi$. The results are presented in detail elsewhere (Loo and Chowdhury 2018).

As a demonstration, for a singly reinforced rectangular section with $b=$ $250 \mathrm{~mm}, d=500 \mathrm{~mm}, f_{\mathrm{c}}^{\prime}=50 \mathrm{MPa}$, and Class $\mathrm{N}$ reinforcement only $\left(f_{\mathrm{sy}}=\right.$ $500 \mathrm{MPa}$ ), the reliable moment capacities for the following reinforcement cases were calculated using provisions of both AS 3600-2009 and AS 36002018:
(a) $A_{\mathrm{st}}=1500 \mathrm{~mm}^{2}$
(b) $A_{\mathrm{st}}=9000 \mathrm{~mm}^{2}$
(c) a 'balanced' design
(d) with the maximum allowable reinforcement ratio $\left(p_{\text {all }}\right)$
(e) $A_{\text {st }}=4500 \mathrm{~mm}^{2}$.

The results are tabulated in Table 1 for comparison. As can be seen from Table 1, the ultimate moment capacities for different reinforcement cases differ very little while reliable moment capacities varying to slightly larger extents mainly because of increase in $\phi$ values in AS 3600-2018. Similar minor variations in moment capacities were observed for all other problems even for non-standard and circular sections (Loo and Chowdhury 2018).

As for design examples, these changes made no difference at all in reinforcement requirements and sectional dimensions (Loo and Chowdhury 2018) for any of the worked problems which include all section types (rectangular and flanged) and reinforcement details (singly- and doublyreinforced). 
Table 1. Comparison between AS 3600-2009 and AS 3600-2018 for the Analysis Problem

\begin{tabular}{|c|c|c|c|c|c|c|}
\hline $\begin{array}{c}\text { Reinforcement } \\
\text { Case }\left(A_{\text {st }} \text { values }\right)\end{array}$ & \multicolumn{2}{|c|}{ As per AS 3600-2009 } & \multicolumn{3}{|c|}{ As per AS 3600-2018 } \\
\cline { 2 - 7 } & $\begin{array}{c}M_{\mathrm{u}} \\
(\mathrm{kNm})\end{array}$ & $\phi$ & $\begin{array}{c}\phi M_{\mathrm{u}} \\
(\mathrm{kNm})\end{array}$ & $\begin{array}{c}M_{\mathrm{u}} \\
(\mathrm{kNm})\end{array}$ & $\phi$ & $\begin{array}{c}\phi M_{\mathrm{u}} \\
(\mathrm{kNm})\end{array}$ \\
\hline (a) $A_{\text {st }}=1500 \mathrm{~mm}^{2}$ & 348.5 & 0.8 & 278.8 & 346.0 & 0.85 & 294.1 \\
\hline (b) $A_{\text {st }}=9000 \mathrm{~mm}^{2}$ & 964.2 & 0.6 & 578.5 & 978.5 & 0.65 & 636.0 \\
\hline (c) balanced $p_{\mathrm{t}}=p_{\mathrm{B}}$ & 819.5 & 0.6 & 491.7 & 858.7 & 0.65 & 558.2 \\
\hline (d) maximum $p_{\mathrm{t}}=p_{\text {all }}$ & 639.6 & 0.757 & 484.2 & 680.4 & 0.807 & 549.1 \\
\hline (e) $A_{\text {st }}=4500 \mathrm{~mm}^{2}$ & 840.7 & 0.6 & 504.4 & 860.4 & 0.65 & 559.3 \\
\hline
\end{tabular}

\section{Design for Shear and Torsion}

Shear behaviour of reinforced concrete beams is very complicated due to many parameters such as concrete compressive strength, stirrup ratio, shear span-to-depth ratio, longitudinal reinforcement ratio, and so on (Lee et al. 2010, Labib et al. 2013, Mofidi and Chaallal 2014, Chiu et al. 2016, ElSayed and Shuraim 2016, Zhang et al. 2017, Jude et al. 2018). It is, therefore, hard to evaluate shear strength of reinforced concrete beams. Even shear design provisions around the world are much different through each other, even from theoretical perspective, especially for reinforced concrete beams with stirrups (Eurocode 2 2004, ACI 318 2014, CSA A23.3 2014, AS 3600 2018). Similar is the case for torsion design.

Complexities and computational efforts introduced in AS 3600-2018 are most severe for design of reinforced and prestressed concrete for shear and torsion. Apart from the required increase in capacity reduction factor $(\phi)$ for shear and torsion consideration from 0.7 to 0.75 , some substantial changes have been introduced. These, together with their effectiveness, are discussed in the following sections.

\section{Complexities}

The nominal maximum shear force that can be carried by a beam is limited by the crushing strength of the web, $V_{\text {u.max }}$, was given in AS 36002009 as

$$
V_{\mathrm{u} \text { max }}=0.2 f_{\mathrm{c}}^{\prime} b_{\mathrm{w}} d_{\mathrm{o}}
$$

where $b_{\mathrm{w}}$ is the width of the web of the beam.

On the other hand, $V_{\text {u.max }}$ is to be calculated in a much more complicated manner in AS 3600-2018, as

$$
V_{\text {u. } \max }=0.55\left[f_{\mathrm{c}}^{\prime} b_{w} d_{v}\left(\frac{\cot \theta_{\mathrm{v}}}{1+\cot ^{2} \theta_{\mathrm{v}}}\right)\right]
$$


where effective shear depth, $d_{\mathrm{v}}$, shall be taken as the greater of $0.72 D$ or $0.9 d$ and the angle of inclination of the compression strut $\left(\theta_{\mathrm{v}}\right)$ shall be calculated as

$$
\theta_{\mathrm{v}}=\left(29+7000 \varepsilon_{\mathrm{x}}\right)
$$

in which, the longitudinal strain in concrete for shear, $\varepsilon_{\mathrm{x}}$, at the mid-depth of the section is calculated as

$$
\varepsilon_{\mathrm{x}}=\frac{\left|M^{*} / d_{\mathrm{v}}\right|+\left|V^{*}\right|+0.5 N^{*}}{2 E_{\mathrm{s}} A_{\mathrm{st}}} \leq 3.0 \times 10^{-3}
$$

$M^{*}$ and $V^{*}$ are absolute values and $M^{*} \geq V^{*} d_{v}$ and $N^{*}$ is the axial force acting on the section and is taken as positive for tension and negative for compression.

Alternatively, $\theta_{\mathrm{v}}$ may be taken as $36^{\circ}$ for $N^{*}=0, f_{\mathrm{sy}} \leq 500$ $\mathrm{MPa}, f_{\mathrm{c}}^{\prime} \leq 65 \mathrm{MPa}$ and maximum aggregate size not less than $10 \mathrm{~mm}$.

Concrete contribution to shear strength, $V_{\mathrm{uc}}$, is given by the following in AS 3600-2009:

$$
V_{\mathrm{uc}}=\beta_{1} \beta_{2} \beta_{3} b_{\mathrm{w}} d_{\mathrm{o}} f_{\mathrm{cv}} \sqrt[3]{\frac{A_{\mathrm{st}}}{b_{\mathrm{w}} d_{\mathrm{o}}}}
$$

where $\beta_{1}, \beta_{2}$ and $\beta_{3}$ can be computed using simple formulas and/or taken as equal to 1 , and $f_{\mathrm{cv}}=\sqrt[3]{f_{\mathrm{c}}^{\prime}}$.

In AS 3600-2018, the determination of $V_{\mathrm{uc}}$, requires much more computational efforts in a rather complex way. Or, $V_{\mathrm{uc}}$, is given as

$$
V_{\mathrm{uc}}=k_{\mathrm{v}} b_{\mathrm{w}} d_{\mathrm{v}} \sqrt{f_{\mathrm{c}}^{\prime}}
$$

where $\sqrt{f_{\mathrm{c}}^{\prime}}$ is not to exceed 8.0 MPa, the strut angle $\theta_{\mathrm{v}}$ is calculated using Equations (11) and (12) as above and $k_{\mathrm{v}}$ is determined as elaborated below.

(a) For $A_{\mathrm{sv}}<A_{\mathrm{sv} . \mathrm{min}}$ :

$$
k_{\mathrm{v}}=\left[\frac{0.4}{1+1500 \varepsilon_{\mathrm{x}}}\right]\left[\frac{1300}{1000+k_{\mathrm{dg}} d_{\mathrm{v}}}\right]
$$

where

(i) $f_{\mathrm{c}}^{\prime} \leq 65 \mathrm{MPa}$ and not light-weight concrete 


$$
k_{\mathrm{dg}}=\left[\frac{32}{(16+a)}\right] \geq 0.8
$$

$a$ is the maximum nominal aggregate size and for $a$ not less than 16 $\mathrm{mm}, k_{\mathrm{dg}}$ may be taken as 1.0 .

(ii) $f_{c}^{\prime}>65 \mathrm{MPa}$ or light-weight concrete

$$
k_{\mathrm{dg}}=2.0
$$

(b) For $A_{\mathrm{sv}}>A_{\mathrm{sv} \cdot \min }$ :

$$
k_{\mathrm{v}}=\left[\frac{0.4}{1+1500 \varepsilon_{\mathrm{x}}}\right]
$$

Alternatively, for $N^{*}=0, f_{\text {sy }} \leq 500 \mathrm{MPa}, f_{\mathrm{c}}^{\prime} \leq 65 \mathrm{MPa}$ and maximum aggregate size not less than $10 \mathrm{~mm}, k_{\mathrm{v}}$ may be determined as follows.

(a) For $A_{\text {sv }}<A_{\text {sv.min: }}$ :

$$
k_{\mathrm{v}}=\left[\frac{200}{1000+1.3 d_{\mathrm{v}}}\right] \leq 0.10
$$

(b) For $A_{\mathrm{sv}}>A_{\mathrm{sv} . \mathrm{min}}$ :

$$
k_{\mathrm{v}}=0.15
$$

Finally, transverse shear reinforcement is to be provided in all regions where $V^{*}>\phi V_{\text {uc }}$ or in which the overall depth of the member $D \geq 750 \mathrm{~mm}$.

For torsional design, even though the basic principles were still the same, the computations and formulas used are made a lot more complicated - not to mention the extra computational efforts required.

In AS 3600-2009, for combined torsion and shear and for all section types,

$$
T^{*} \leq \phi T_{\mathrm{u}, \max }\left(1-\frac{V^{*}}{\phi V_{\mathrm{u}, \max }}\right)
$$

where $V_{\text {u.max }}$ is calculated using Equation (9) and the maximum capacity of a beam in torsion, $T_{\mathrm{u} . \max }$ is given by

$$
T_{\mathrm{u}, \max }=0.2 f_{\mathrm{c}}^{\prime} J_{\mathrm{t}}
$$

In Equation (22), $J_{\mathrm{t}}$ is the torsional modulus and is given by some simple formulas. 
In AS 3600-2018, on the other hand, for combined shear and torsion, the following are to be satisfied.

(a) For box sections:

(i) Where wall thickness $t_{\mathrm{w}}>A_{\mathrm{oh}} / u_{\mathrm{h}}$

$$
\frac{V^{*}}{b_{\mathrm{w}} d_{\mathrm{v}}}+\frac{T^{*} u_{\mathrm{h}}}{1.7 A_{\mathrm{oh}}^{2}} \leq \frac{\phi V_{\mathrm{u} \cdot \max }}{b_{\mathrm{w}} d_{\mathrm{v}}}
$$

(ii) Where wall thickness $t_{\mathrm{w}} \leq A_{\mathrm{oh}} / u_{\mathrm{h}}$

$$
\frac{V^{*}}{b_{\mathrm{w}} d_{\mathrm{v}}}+\frac{T^{*}}{1.7 t_{\mathrm{w}} A_{\mathrm{oh}}} \leq \frac{\phi V_{\text {u.max }}}{b_{\mathrm{w}} d_{\mathrm{v}}}
$$

(b) For other sections:

$$
\sqrt{\left[\frac{V^{*}}{b_{\mathrm{w}} d_{\mathrm{v}}}\right]^{2}+\left[\frac{T^{*} u_{\mathrm{h}}}{1.7 A_{\mathrm{oh}}^{2}}\right]^{2}} \leq \frac{\phi V_{\mathrm{umax}}}{b_{\mathrm{w}} d_{\mathrm{v}}}
$$

where

$A_{\text {oh }}=$ areas enclosed by centre-line of exterior closed transverse torsion reinforcement, including area of holes (if any)

$u_{\mathrm{h}}=$ perimeter of the centre-line of the closed transverse torsion reinforcement

$V_{\mathrm{u} \text { max }}$ is calculated using Equation (10) but for the determination of $\theta_{\mathrm{v}}$, the longitudinal strain in the concrete at the mid-depth of the section, $\varepsilon_{\mathrm{x}}$, subjected to shear and torsion is determined as

$$
\varepsilon_{\mathrm{x}}=\frac{\left|\frac{M^{*}}{d_{\mathrm{v}}}\right|+\sqrt{\left.V^{*}\right|^{2}+\left[\frac{0.9 T^{*} u_{\mathrm{h}}}{2 \mathrm{~A}_{\mathrm{o}}}\right]^{2}}+0.5 N^{*}}{2 E_{\mathrm{s}} \mathrm{A}_{\mathrm{tt}}} \leq 3.0 \times 10^{-3}
$$

In Equation (26), $A_{\mathrm{o}}=$ area enclosed by shear flow path, including any area of holes therein and $N^{*}$ is taken as positive for tension and negative for compression. Also, $M^{*}$ and $V^{*}$ are absolute values and

$$
M^{*} \geq d_{v} \sqrt{\left.V^{*}\right|^{2}+\left[\frac{0.9 T^{*} u_{\mathrm{h}}}{2 A_{0}}\right]^{2}}
$$

Also, for consideration of torsional effects, the plain-concrete beam strength in pure torsion, $T_{\text {uc }}$, was given in AS 3600-2009 as 


$$
T_{\mathrm{uc}}=J_{\mathrm{t}}\left(0.3 \sqrt{f_{\mathrm{c}}^{\prime}}\right)
$$

But in AS 3600-2018, this was replaced by torsional cracking moment, $T_{\text {cr }}$, and was given by a more complicated formula as

$$
T_{\mathrm{cr}}=\left(0.33 \sqrt{f_{\mathrm{c}}^{\prime}}\right) \frac{A_{\mathrm{cp}}^{2}}{u_{\mathrm{c}}}
$$

where

$A_{\mathrm{cp}}=$ total area enclosed by the outside perimeter of the concrete crosssection

$u_{\mathrm{c}}=$ the length of the outside perimeter of the concrete cross-section.

Finally, for the transverse reinforcement (ties) to be fully effective, longitudinal bars are needed. Thus, longitudinal torsional steel in addition to the main reinforcement for bending must be provided in the bending tensile and compressive zones. Formulas for calculating the additional longitudinal reinforcement requirements for torsion, in both the tensile and compressive zones, are also made much more complicated in AS 3600-2018. For brevity, these new changes are not reproduced herein. Interested readers may refer to the Standard itself (AS 3600-2018) for details.

\section{Effectiveness}

Calculations for design of reinforced concrete for shear and torsion have been carried out using the updated specifications given in AS 36002018, as well as those available in the superseded AS 3600-2009 for several practical problems. These are presented in detail elsewhere (Loo and Chowdhury 2018).

A summary of some of the worked problems for shear design using AS 3600-2009 and AS 3600-2018 is presented in Table 2 for comparison. 
Table 2. Comparison between AS 3600-2009 and AS 3600-2018 for Shear Design Problems

\begin{tabular}{|c|c|c|c|c|c|c|c|}
\hline \multirow{2}{*}{$\begin{array}{l}\text { Prob- } \\
\text { lem } \\
\text { No. }\end{array}$} & \multirow{2}{*}{$\begin{array}{l}\text { Design } \\
V^{*}(\mathrm{kN})\end{array}$} & \multicolumn{3}{|c|}{ As per AS 3600-2009 } & \multicolumn{3}{|c|}{ As per AS 3600-2018 } \\
\hline & & $\begin{array}{l}V_{\text {u.max }} \\
(\mathrm{kN})\end{array}$ & $\begin{array}{c}V_{\mathrm{uc}} \\
(\mathrm{kN})\end{array}$ & $\begin{array}{c}\text { Final } \\
\text { Design }\end{array}$ & $\begin{array}{l}V_{\mathrm{u} \cdot \max } \\
(\mathrm{kN})\end{array}$ & $\begin{array}{c}V_{\mathrm{uc}} \\
(\mathrm{kN})\end{array}$ & $\begin{array}{c}\text { Final } \\
\text { Design }\end{array}$ \\
\hline 1 & 137.73 & 380.0 & 141.6 & $\begin{array}{c}\text { R10@ } \\
225 \text { mm }\end{array}$ & 802.7 & 48.6 & $\begin{array}{c}\text { R10@ } \\
125 \\
\text { mm }\end{array}$ \\
\hline 2 & 248.76 & 430.0 & 108.2 & $\begin{array}{c}\text { R10@ } 75 \\
\text { mm }\end{array}$ & 506.1 & 58.05 & $\begin{array}{l}\text { R10@ } \\
75 \text { mm }\end{array}$ \\
\hline 3 & 537.73 & 987.0 & 218.2 & $\begin{array}{c}\text { N16@ } \\
285 \text { mm }\end{array}$ & 1112.2 & 127.6 & $\begin{array}{l}\text { N16@ } \\
245 \\
\text { mm }\end{array}$ \\
\hline 4 & 334.61 & 1658.9 & 260.3 & $\begin{array}{c}\text { N12@ } \\
300 \text { mm }\end{array}$ & 1876.5 & 190.4 & $\begin{array}{c}\text { N12@ } \\
300 \\
\text { mm }\end{array}$ \\
\hline 5 & 583.14 & 1570.6 & 89.5 & $\begin{array}{c}\text { N10@85 } \\
\text { mm }\end{array}$ & 1742.8 & 229.4 & $\begin{array}{c}\text { N10@ } \\
145 \\
\text { mm }\end{array}$ \\
\hline 6 & 478.36 & 1316.3 & 210.1 & $\begin{array}{c}\text { N10@ } \\
155 \text { mm }\end{array}$ & 1474.5 & 154.5 & $\begin{array}{l}\text { N10@ } \\
125 \\
\text { mm }\end{array}$ \\
\hline 7 & 130.47 & 486.4 & 139.8 & $\begin{array}{c}\text { R10@ } \\
225 \text { mm }\end{array}$ & 542.3 & 55.0 & $\begin{array}{c}\text { R10@ } \\
145 \\
\text { mm }\end{array}$ \\
\hline 8 & 876.60 & 2165.8 & 394.7 & $\begin{array}{l}\text { N12@ } \\
165 \text { mm }\end{array}$ & 2375.4 & 241.0 & $\begin{array}{c}\text { N12@ } \\
130 \\
\text { mm }\end{array}$ \\
\hline 9 & 228.69 & 420.0 & 98.3 & $\begin{array}{c}\text { R10@ } 85 \\
\text { mm }\end{array}$ & 494.3 & 56.7 & $\begin{array}{l}\text { R10@ } \\
90 \mathrm{~mm}\end{array}$ \\
\hline 10 & 1180.7 & 2030.4 & 328.7 & $\begin{array}{c}\text { N12@ } 75 \\
\text { mm }\end{array}$ & 2392.6 & 101.9 & $\begin{array}{l}\text { N12@ } \\
45 \mathrm{~mm} \\
\end{array}$ \\
\hline 11 & 476.0 & 1776.0 & 256.5 & $\begin{array}{c}\text { N12@ } \\
195 \text { mm }\end{array}$ & 1844.3 & 311.4 & $\begin{array}{c}\text { N12@ } \\
300 \\
\text { mm }\end{array}$ \\
\hline 12 & 325.17 & 998.4 & 23.3 & $\begin{array}{l}\text { N12@ } \\
180 \text { mm }\end{array}$ & 1168.2 & 132.7 & $\begin{array}{c}\text { N12@ } \\
245 \\
\text { mm } \\
\end{array}$ \\
\hline 13 & 138.31 & 430.0 & 108.2 & $\begin{array}{c}\text { R10@ } \\
250 \text { mm }\end{array}$ & 497.4 & 69.7 & $\begin{array}{c}\text { R10@ } \\
190 \\
\text { mm }\end{array}$ \\
\hline
\end{tabular}

As obvious in Table 2, the final designs for shear varied rather little for most of the problems. In fact, for the lower range of design shear values, where the maximum spacing for shear reinforcement allowed by the Standard governed, there are no difference in the final design. Cases where the final design varied significantly are beams subjected to large axial forces together with design shear forces. For example, Problems 5, 10, 11, 12 and 13 are subjected to very large inclined forces. Interested readers may find further details elsewhere (Loo and Chowdhury 2018). 
Similar observations have also been made for torsion design in that little or no variations can be found in the outcomes.

\section{Deflection}

It has been concluded in a comparative study of nine analytical methods that the effective moment of inertia approach is a convenient and accurate one for deflection calculations (Loo and Wong 1984). It is convenient because the standard deflection formulas are readily applicable with modifications only to the bending rigidity term or $E I$.

For a cracked reinforced concrete beam, $E$ is replaced by the modulus of elasticity for concrete, $E_{\mathrm{c}}$, and for $I$ an effective value $I_{\text {ef }}$ can be used where in general,

$$
I_{\mathrm{cr}} \leq I_{\mathrm{ef}} \leq I_{\mathrm{g}}
$$

in which $I_{\mathrm{g}}$ is the gross moment of inertia of the uncracked beam section and $I_{\mathrm{cr}}$ is that of a fully cracked beam.

\section{Complexities}

The empirical Branson formula for calculating the effective moment of inertia $\left(I_{\mathrm{ef}}\right)$ has been adopted in the AS 3600-2009 and several other major codes of practice including that of the American Concrete Institute (see Loo and Wong 1984). Taking into consideration the stiffening effects of the concrete in tension between cracks (i.e. tension stiffening), the formula is explicit and all-encompassing. That is

$$
I_{\text {ef }}=I_{\text {cr }}+\left(I_{\mathrm{g}}-I_{\mathrm{cr}}\right)\left(\frac{M_{\mathrm{cr}}}{M_{\mathrm{s}}}\right)^{3} \leq I_{\text {ef.max }}
$$

where $I_{\text {ef.max }}=I_{\mathrm{g}}$ for $p_{\mathrm{t}} \geq 0.005$ and $I_{\text {ef.max }}=0.6 I_{\mathrm{g}}$ for $p_{\mathrm{t}}<0.005$, which indicates that the Branson formula in its original form underestimates the deflection of very lightly reinforced beams (see Gilbert 2008).

The quantity $M_{\mathrm{s}}$ is the maximum bending moment at the section due to the short-term serviceability load under consideration, and $M_{\mathrm{cr}}$ is the cracking moment.

In AS 3600-2018, the formula for calculating $I_{\mathrm{ef}}$ is modified as follows with the same limiting values for $I_{\text {ef.max }}$ as in Equation (31):

$$
I_{\text {ef }}=\frac{I_{\text {cr }}}{1-\left(1-\frac{I_{\mathrm{cr}}}{I_{\mathrm{g}}}\right)\left(\frac{M_{\mathrm{cr}}}{M_{\mathrm{s}}}\right)^{2}} \leq I_{\text {ef.max }}
$$




\section{Effectiveness}

To investigate the effectiveness of the changes made to the $I_{\mathrm{ef}}$ formula, calculations for several deflection problems have been made using the provisions given in AS 3600-2018, as well as those available in the superseded AS 3600-2009. The outcomes are detailed elsewhere (Loo and Chowdhury 2018).

As a demonstration, the midspan deflection of a simply supported beam is calculated. With $L_{\mathrm{ef}}=10 \mathrm{~m}, b=350 \mathrm{~mm}, d=580 \mathrm{~mm}, D=650 \mathrm{~mm}$ and $p_{\mathrm{t}}=0.01$, the beam is under a combined dead load including self-weight ( $g$ $=8 \mathrm{kN} / \mathrm{m})$ and live load $(q=8 \mathrm{kN} / \mathrm{m})$. The values for $E_{\mathrm{c}}, E_{\mathrm{s}}$ and $f_{\mathrm{c}}^{\prime}$ are taken as $26000 \mathrm{MPa}, 200000 \mathrm{MPa}$ and $32 \mathrm{MPa}$, respectively and the beam is assumed to form part of a domestic floor system with the shrinkage effects ignored.

A comparison of results shows that using AS 3600-2009, the value of $I_{\mathrm{ef}}$ is $3750 \times 10^{6} \mathrm{~mm}^{4}$. This is very close to AS 3600-2018 value of $3717 \times 10^{6} \mathrm{~mm}^{4}$. Similarly, the corresponding midspan deflections are $18.2 \mathrm{~mm}$ and $18.3 \mathrm{~mm}$.

Likewise, little or no variations in deflection results were observed for all other problems attempted in the said investigation.

\section{Conclusions}

Significant changes and/or updates have been made in AS 3600-2018, the latest Australian Standard for Concrete Structures. These are mainly in the requirements for configuring the stress-block, calculating the capacity reduction factor $\phi$, evaluating the shear and torsional strengths of concrete members, as well as in estimating the effective moment of inertia $I_{\text {ef. }}$

These modifications have resulted in more complicated procedures requiring added computational efforts. Comparisons of results tend to show that such additional efforts have in most cases produced no significant difference in outcomes from the superseded AS 3600-2009. Where there are differences, the new Standard would lead to less conservative designs.

\section{References}

ACI 318 (2014) Building Code Requirements for Structural Concrete and Commentary. ACI 318-14/ACIR-14. Farmington Hills, MI, American Concrete Institute.

AS 1480-1982 (1982) SAA Concrete Structures Code. North Sydney: Standards Association of Australia.

AS 1481-1978 (1978) SAA Prestressed Concrete Code. Standards Association of Australia, North Sydney.

AS 3600-1988 (1988) Concrete Structures. North Sydney: Standards Association of Australia.

AS 3600-1994 (1994) Concrete Structures. Homebush: Standards Australia.

AS 3600-2001 (2001) Concrete Structures. Sydney: Standards Australia International 
Ltd.

AS 3600-2009 (2009) Concrete Structures. Sydney: Standards Australia Limited.

AS 3600-2018 (2018) Concrete Structures. Sydney: Standards Australia Limited.

Barchi M, Azadbakht M, Hadad M (2010) Evaluating the Ductility and Shear Behaviour of Carbon Fibre Reinforced Polymer and Glass Fibre Reinforced Polymer Reinforced Concrete Columns. The Structural Design of Tall and Special Buildings 21(4): 249-264.

Chiu CK, Ueda T, Chi KN, Chen SQ (2016) Shear Crack Control for High Strength Reinforced Concrete Beams Considering the Effects of Shear-Span to Depth Ratio. International Journal of Concrete Structures and Materials 10(4): 407-424.

CSA-A23.3 (2014) Design of Concrete Structures. Canadian Standards Association, Rexdale.

El-Sayed AK, Shuraim AB (2016) Experimental Verification of Resistance-Demand Approach for Shear of HSC Beams. International Journal of Concrete Structures and Materials 10(4): 513-525.

Eurocode 2 (2004) Design of Concrete Structures, Part 1-1: General Rules and Rules for Buildings. Brussels, Belgium: European Committee for Standardisation, 230.

Gilbert RI (2008) Revisiting the Tension Stiffening Effect in Reinforced Concrete Slabs. Australian Journal of Structural Engineering 8(3): 189-196.

Ho JCM (2011) Limited Ductility Design of Reinforced Concrete Columns for Tall Buildings in Low to Moderate Seismicity Regions. The Structural Design of Tall and Special Buildings 20(1): 102-120.

Ibrahim HHH, MacGregor JG (1997) Modification of the ACI Rectangular Stress Block for High-Strength Concrete. ACI Structural Journal 94(1): 40-48. DOI= $10.14359 / 459$.

Jude EO, Oh CH, Lee SC (2018) Single Web Shear Element Model for Shear Strength of RC Beams with Stirrups. International Journal of Concrete Structures and Materials. DOI: 10.1186/s40069-018-0252-9.

Kaar PH, Hanson NW, Capell HT (1978) Stress-Strain Characteristics of High Strength Concrete. Douglas McHenry International Symposium on Concrete and Concrete Structures, SP-55. Farmington Hills, MI: American Concrete Institute, 161-185.

Labib EL, Mo YL, Hsu TTC (2013) Shear Cracking of Prestressed Girders with High Strength Concrete. International Journal of Concrete Structures and Materials 7(1): 71-78.

Lee SC, Cho JY, Oh BH (2010) Shear Behavior of Large-Scale Post-Tensioned Girders with Small Shear Span-Depth Ratio. ACI Structural Journal 107(2): 137145.

Loo YC, Chowdhury SH (2018) Reinforced and Prestressed Concrete. $3^{\text {rd }}$ Edition (Supplement and Solution Manual). Melbourne: Cambridge University Press.

Loo YC, Wong YW (1984) Deflection of Reinforced Box Beams under Repeated Loadings. ACI Structural Journal 81(1): 87-94.

Mofidi A, Chaallal O (2014) Tests and Design Provisions for Reinforced-Concrete Beams Strengthened in Shear Using FRP Sheets and Strips. International Journal of Concrete Structures and Materials 8(1): 117-128.

Nedderman H (1973) Flexural Stress Distribution in Very High Strength Concrete. M.A.Sc. Thesis. Department of Civil Engineering, University of Texas, Arlington.

Ozbakkaloglu T, Saatcioglu M (2004) Rectangular Stress Block for High-Strength Concrete. ACI Structural Journal 101(4): 475-483. DOI= 10.14359/13333.

Tan TH, Nguyen NB (2004) Determination of Stress-Strain Curves of Concrete from Flexure Tests. Magazine of Concrete Research 56(4): 243-250. 
Tan TH, Nguyen NB (2005) Flexural Behavior of Confined High-Strength Concrete Columns. ACI Structural Journal 102(2): 198-205.

Yan ZH, Au FTK (2010) Nonlinear Dynamic Analysis of Frames with Plastic Hinges at Arbitrary Locations. The Structural Design of Tall and Special Buildings 19(7): 778-801.

Zhang T, Visintin P, Oehlers DJ (2017) Shear strength of RC beams subjected to axial load. Australian Journal of Civil Engineering 15(1): 32-48. DOI: 10.1080/14488 353.2017.1370685.

Zhu Y, Su RKL (2010) Seismic Behavior of Strengthened Reinforced Concrete Coupling Beams by Bolted Steel Plates, Part 2: Evaluation of Theoretical Strengths. Structural Engineering and Mechanics 34(5): 563-580. 
